\title{
PENTOLINIUM FOR CONTROL OF REFLEX HYPERTENSION IN SPINAL CORD INJURED PATIENTS
}

\author{
By Stanley Muravchick, M.D., Ph.D., B. Thomas Brown, M.D., Hernan \\ Carrion, M.D., Victor A. Politano, M.D. and Vicente Pallares, M.D. \\ Departments of Anesthesiology (Drs Muravchick and Pallares) and Urology (Drs Brown, \\ Carrion and Politano), University of Miami School of Medicine, and the Spinal Cord \\ Injury Service, Fackson Memorial Hospital and the Miami Veterans Administration \\ Hospital, Miami, Florida 33125, U.S.A.
}

Abstract. Ganglioplegia was produced by intravenous infusion of pentolinium tartrate $5 \mathrm{mg}$ to control reflex hypertension in 29 patients with chronic spinal cord injuries undergoing 32 elective surgical procedures. The patient group with lesions above the first thoracic segment ( $\mathrm{T}$ I) demonstrated significant but moderate intraoperative elevation of both systolic and diastolic pressure whether pentolinium was given prior to or during surgical stimulation. Patients with lesions below T I had no significant pressure elevations with either mode of therapy. Pentolinium ganglioplegia can saf ely maintain blood pressure within reasonable limits in these patients; some increase in dosage may be required in patients with lesions above $\mathrm{T}$ I.

Key words: Pentolinium; Reflex hypertension; Spinal cord injury.

\section{Introduction}

AuTONOMIC hyperreflexia $(\mathrm{AH})$ may produce paroxysmal arterial hypertension in spinal cord injured patients undergoing perineal, urinary bladder, or orthopaedic surgery (Guttman and Whitteridge, I947; Kurnick, 1956; Caron and Bors, 1970; Johnson et al., I975; Guttman, 1976, Snow et al., 1977). The severity of the potential stigmata of throbbing headache, convulsion, and cerebrovascular accident requires that the intraoperative management of these patients permit control of reflex-mediated vasoconstriction. Although general anaesthesia and subarachnoid block have been advocated for prevention of $\mathrm{AH}$ (Rocco and Vandam, 1959; Caron and Bors, I970), susceptible patients generally have complete cord transection with loss of sensation below the lesion, and do not require anaesthesia with its attendant hazards. In this study, we have reviewed our experience with a ganglioplegic drug, pentolinium tartrate (Ansolysen) and evaluated its effectiveness in controlling $\mathrm{AH}$ when given before and during surgery.

\section{Methods}

The intraoperative records of 29 adult male patients with chronic, complete cord transection who had undergone a total of 32 surgical or diagnostic procedures from April I975 through February 1977 (Table I) were analysed retrospectively. Hospital documents specified the levels of the cord lesions, all of which occurred at least 4 months prior to surgery, usually as a result of trauma from automobile accidents or gunshot. Lesions above the first thoracic segmant (range $\mathrm{C}_{4}-\mathrm{C} 8$ were defined as 'high lesions; all others were 'low' lesions (range T2-T8). No

${ }^{1}$ Presented in part at the Annual Meeting of the American Society of Anesthesiologists, New Orleans, Louisiana, October 1977. 
patients studied were receiving antihypertensive medications prior to surgery; all were given narcotic and/or tranquilisers intramuscularly for premedication.

Intraoperative vital signs were obtained from the patients' anaesthesia records, having been measured and recorded by anaesthetists using arm cuff sphygmomanometer and an electrocardiogram. 'Control' values represent vital signs upon initiation of monitoring, with the patient supine upon the operating table, prior to pentolinium or surgery. In 22 procedures, the patients had been 'pre-treated': $5 \mathrm{mg}$ of pentolinium were given intravenously (IV) 5 or $10 \mathrm{~min}$ prior to surgery at the discretion of the anaesthetist or surgeon. This has been a frequent practice with these patients at our hospitals. In the remaining ten procedures ('empirical' treatment), pentolinium had been given in I to $5 \mathrm{mg}$ increments IV during surgery in an attempt to titrate the drug against increases in blood pressure.

For patients who had been pretreated, the 'response to pentolinium' represents

\section{TABLE I}

Patient and lesion characteristics

\begin{tabular}{|c|c|c|c|c|}
\hline $\begin{array}{l}\text { Patient } \\
\text { age (yr) }\end{array}$ & $\begin{array}{c}\text { Patient } \\
\text { weight }(\mathrm{kg})\end{array}$ & $\begin{array}{l}\text { Sensory level } \\
\text { of lesion }\end{array}$ & $\begin{array}{c}\text { Age of } \\
\text { lesion (mos) }\end{array}$ & Surgical procedures \\
\hline ..... & & $\cdots-$ & $\ldots$ & 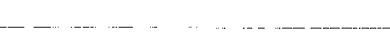 \\
\hline 17 & 99 & $\mathrm{C}_{7}-\mathrm{T}_{\mathrm{I}}$ & 24 & Ext. sphincterotomy \\
\hline I 8 & 64 & $\mathrm{C} 5-\mathrm{C} 6$ & 8 & Cystoscopy \\
\hline I 8 & 55 & $\mathrm{C}_{4}-\mathrm{C}_{5}$ & 12 & Cystoscopy \\
\hline I 7 & 60 & $\mathrm{C}_{5}$ & I I & Ext. sphincerterotomy \\
\hline 19 & 36 & $\mathrm{C}_{5}-\mathrm{C} 6$ & IO & Cystoscopy \\
\hline 42 & 68 & $\mathrm{C} 6-\mathrm{C}_{7}$ & 264 & Ext. sphincterotomy \\
\hline 35 & 99 & $\mathrm{C}_{5}-\mathrm{C} 6$ & I 44 & Cystoscopy \\
\hline 20 & 87 & $\mathrm{C}_{4}$ & 22 & Ext. sphincterotomy \\
\hline $2 \mathrm{I}$ & $9 \mathrm{I}$ & $\mathrm{C}_{6}-\mathrm{C}_{7}$ & 4 & Gluteal flap \\
\hline 28 & 63 & $\mathrm{C}_{4}-\mathrm{C}_{5}$ & $\begin{array}{l}4 \\
5\end{array}$ & Cystoscopy \\
\hline 20 & 68 & $\mathrm{C} 5-\mathrm{C} 6$ & 9 & Cystoscopy \\
\hline 35 & I 4 & $\mathrm{C}_{5}-\mathrm{C} 6$ & 120 & Penile prosthesis \\
\hline I9 & unknown & $\mathrm{C}_{5}-\mathrm{C} 6$ & 4 & Cystoscopy \\
\hline 28 & 55 & C6 & 17 & $\begin{array}{l}\text { Cystoscopy, circumcision, } \\
\text { repair ureterocutaneous } \\
\text { fistula }\end{array}$ \\
\hline 23 & 50 & $\mathrm{C}_{7}$ & 6 & Ext. sphinct., cystoscopy \\
\hline I6 & unknown & $\mathrm{C}_{5}-\mathrm{C} 6$ & 6 & Ext. sphinct., cystoscopy \\
\hline 50 & 80 & $\mathrm{C}_{7}$ & 7 & Ext. sphincterotomy \\
\hline 36 & 75 & $\mathrm{C}_{7}$ & 6 & Ext. sphincterotomy \\
\hline I9 & 59 & $\mathrm{~T} 2$ & I I & Ext. sphincterotomy \\
\hline 20 & 61 & $\mathrm{~T}_{3}-\mathrm{T}_{4}$ & 66 & Cystoscopy \\
\hline 28 & 80 & $\mathrm{~T}_{4}$ & 43 & $\begin{array}{l}\text { Cystoscopy } \\
\text { Abscess drainage }\end{array}$ \\
\hline 53 & 64 & $\mathrm{~T}_{4}$ & 252 & Ext. sphinct., cystoscopy \\
\hline 59 & 53 & $\mathrm{~T}_{3}-\mathrm{T}_{4}$ & 372 & Cystoscopy \\
\hline 30 & 58 & $\mathrm{~T}_{7}-\mathrm{T} 8$ & 45 & Ext. sphincterotomy \\
\hline 46 & 63 & $\mathrm{~T}_{7}-\mathrm{T} 8$ & 264 & Ext. sphincterotomy \\
\hline 28 & 59 & $\mathrm{~T}_{2}-\mathrm{T}_{4}$ & 24 & Cystoscopy \\
\hline 27 & 59 & $\mathrm{~T} 6-\mathrm{T}_{7}$ & 84 & Closure suprabubic stoma \\
\hline 39 & 50 & $\mathrm{~T}_{4}-\mathrm{T}_{5}$ & 96 & Inguinal exploration \\
\hline 24 & unknown & $\mathrm{T}_{5}$ & 24 & Debride. sacral ulcer \\
\hline
\end{tabular}


vital signs $5 \mathrm{~min}$ after IV bolus infusion of pentolinium $5 \mathrm{mg}$, prior to surgery. Vital signs subsequently recorded as 'surgical maximum' for these patients were those observed at the point of peak systolic pressure elevation during surgery or cystoscopy, prior to any supplemental pentolinium. For patients treated empirically, 'surgical maximum' represents vital signs observed at the point of peak systolic pressure after a cumulative dose of $5 \mathrm{mg}$ pentolinium had been given intraoperatively.

No patient had sensation below the lesion, and no anaesthetics or other antihypertensives were used during these procedures. Additional increments of pentolinium were given to some patients as indicated by clinical considerations.

Statistical evaluation of the transcribed blood pressures and heart rates consisted of calculation of mean values and standard error, and $t$-test comparisons. A $P$ value of 0.05 or less was the criterion of significance.

\section{Results}

The control systolic and diastolic pressures for all patients studied were $\mathrm{I} 2 \mathrm{I} \cdot \mathrm{O} \pm 4.4 \mathrm{mmHg}$ and $75 \cdot 3 \pm 2.5 \mathrm{mmHg}$, respectively, mean \pm S.E.; control heart rate was $90 \cdot 2 \pm 3 \cdot 0$ beats $/ \mathrm{min}$. Control values for the patients with high lesions were comparable to those for the low lesion group (Table II). Although the low lesion patients demonstrated small numerical increases in both systolic and diastolic pressure during maximum surgical stimulation, neither of these changes proved to be significant when compared to control values. In contrast, patients with high cord lesions had statistically-significant elevations of blood pressure during surgery: systolic and diastolic pressure elevations were significantly greater for the high lesion patients than those observed for the low lesion group.

The mode of pentolinium therapy did not change the cardiovascular response

\section{TABLE II}

Systolic and diastolic arterial blood pressure and heart rate in response to surgery for patients with high (above TI) and low (below TI) spinal cord lesions

\begin{tabular}{|c|c|c|c|}
\hline & $\begin{array}{l}\text { All high lesions } \\
\quad(n=20)\end{array}$ & & $\begin{array}{l}\text { All low lesions } \\
\quad(n=\mathrm{I} 2)\end{array}$ \\
\hline \multicolumn{4}{|c|}{ Systolic pressure $(\mathrm{mm} \mathrm{Hg})$ mean \pm S.E. } \\
\hline Control & $124 \cdot 0 \pm 5 \cdot 4$ & NS & II $6 \cdot 1 \pm 7 \cdot 9$ \\
\hline Surgical maximum & $164 \cdot 5^{*} \pm 6.6$ & $P<0.005$ & I $3 \mathrm{I} \cdot 2 \pm 9 \cdot 7$ \\
\hline Change with surgery & $+40 \cdot 5 \pm 6 \cdot 2$ & $P<0.005$ & $+15 \cdot 2 \pm 6 \cdot 6$ \\
\hline \multicolumn{4}{|c|}{ Diastolic pressure $(\mathrm{mm} \mathrm{Hg})$ mean \pm S.E. } \\
\hline Control & $75 \cdot 0 \pm 3 \cdot I$ & NS & $74 \cdot 8 \pm 4 \cdot 4$ \\
\hline Surgical maximum & $98 \cdot 5^{*} \pm 4 \cdot 6$ & $P<0.0$ I & $79 \cdot 2 \pm 6 \cdot 3$ \\
\hline Change with surgery & $+23.5 \pm 4.4$ & $P<0.005$ & $+3 \cdot 3 \pm 4 \cdot 4$ \\
\hline \multicolumn{4}{|c|}{ Heart rate (beats $/$ min) mean \pm S.E. } \\
\hline Control & $9 \mathrm{I} \cdot 4 \pm 4 \cdot \mathrm{I}$ & NS & $88 \cdot I \pm 3 \cdot 5$ \\
\hline Surgical maximum & $93 \cdot 4 \pm 5 \cdot 2$ & NS & $89 \cdot 2 \pm 2 \cdot 7$ \\
\hline Change with surgery & $+2 \cdot 0 \pm 5 \cdot 6$ & NS & $+\mathrm{I} \cdot \mathrm{I} \pm 2 \cdot 3$ \\
\hline
\end{tabular}

NS, differences between high and low lesion values not significant.

* Significant difference from control, $P<0.05$. 
to surgical stimulation. In the five empirically-treated patients with high lesions (Fig. I, solid black triangles), surgical stimulation produced significant elevation of both systolic and diastolic pressures. The is high-lesion patients who had been pre-treated with pentolinium (open triangles) also demonstrated a significant increase during surgery, but this followed a significant drop in pressure after pentolinium infusion. The mean maximum values for systolic and diastolic pressure of the pre-treated group were numerically smaller but statistically indistinguishable from the corresponding values of the empirically-treated group.

The pre-treated low-lesion patients had mean systolic and diastolic pressures during surgical stimulation which were essentially identical to the control values (Fig. 2). Although the blood pressures of the five empirically treated patients were numerically higher than control, they were not significantly different from control values or from the respective values for pre-treated patients. Unlike high lesion patients, there was no drop in blood pressure after pentolinium infusion. Heart rates were essentially unchanged in both treatment groups.

The mean total dose of pentolinium given to high lesion patients was $7 \cdot 9 \pm 0 \cdot 7$ mg, significantly more than the $5.5 \pm 0.5 \mathrm{mg}$ required by patients with low lesions $(P<0.005)$. Sixty per cent of the patients with high lesions required additional pentolinium beyond the original $5 \mathrm{mg}$, while only 33 per cent of the low-lesion group required more pentolinium for clinically adequate control of pressure. The

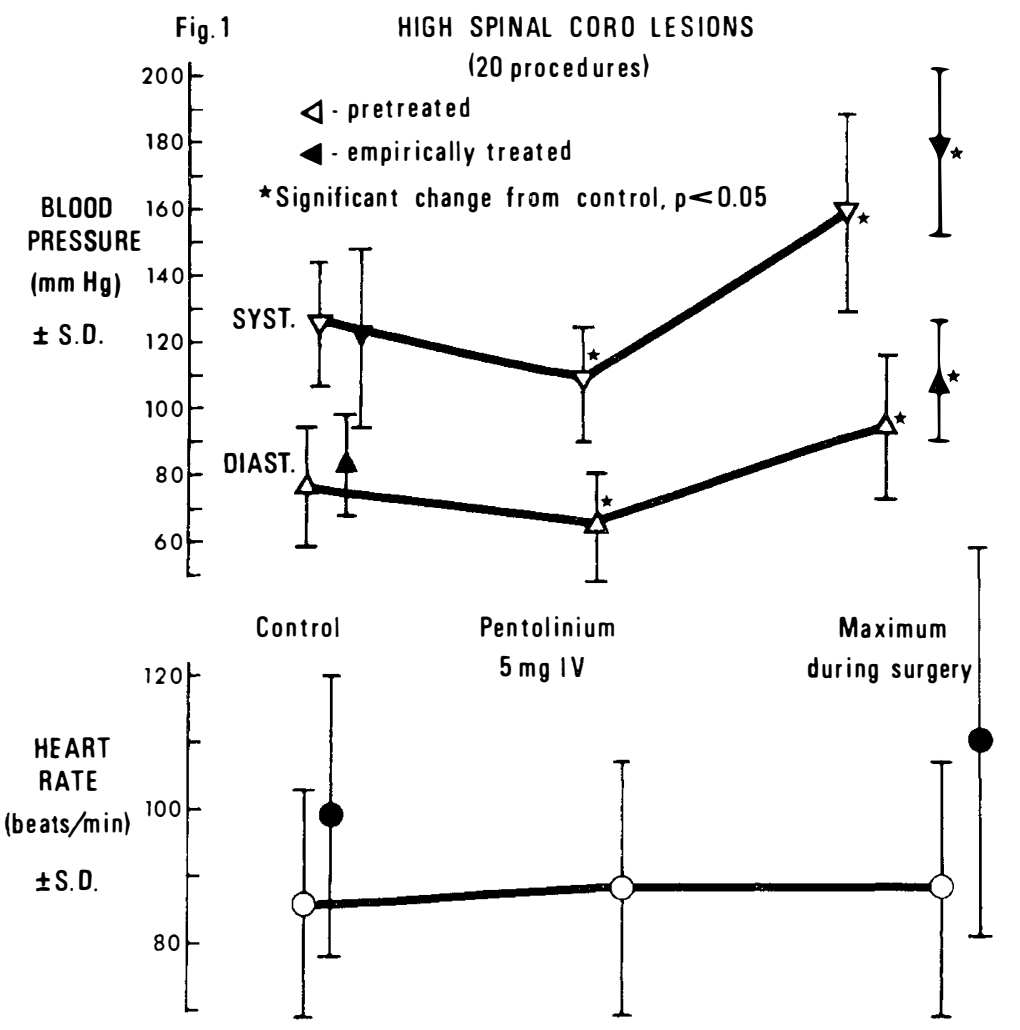

FIG. I.

Cardiovascular response to pentolinium and surgery, spinal cord lesions above TI. Open figures represent pretreated group, closed figures, the empirically-treated group. 


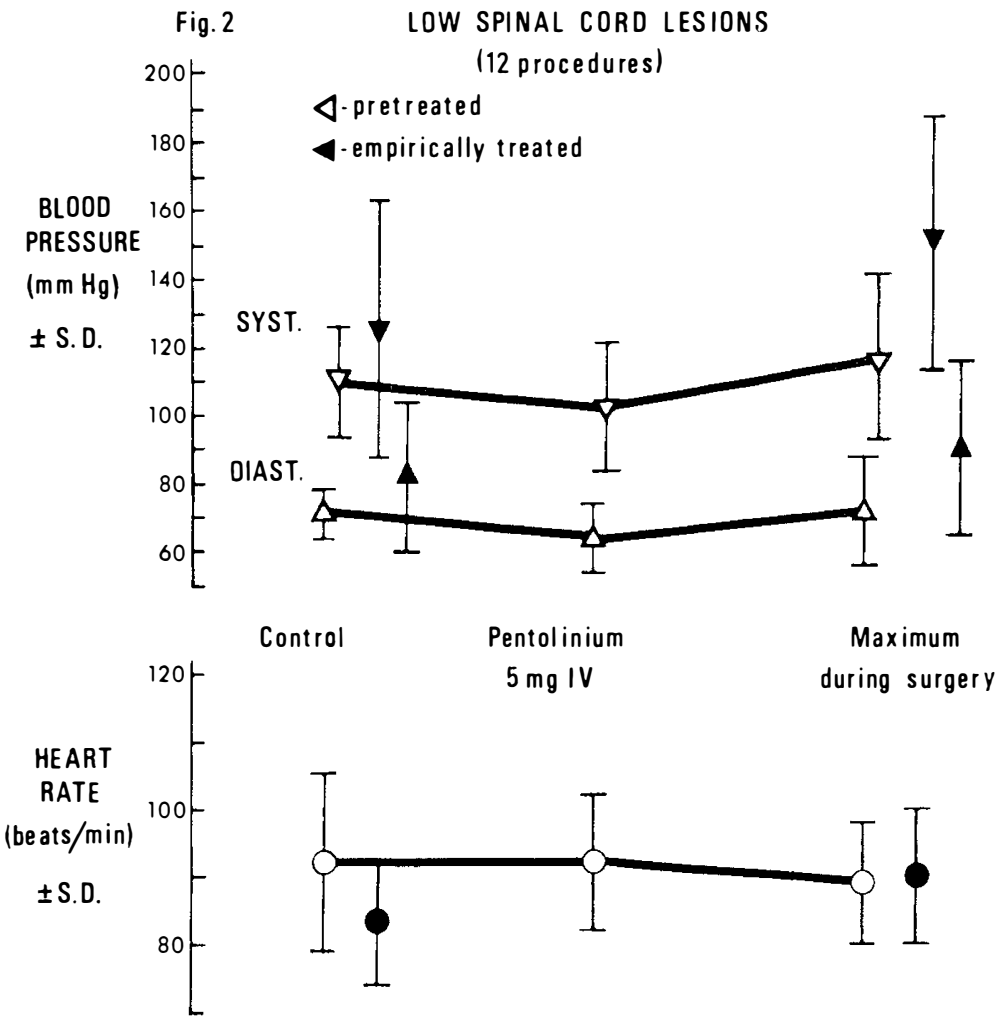

Fig. 2.

Cardiovascular response to pentolinium and surgery, spinal cord lesions below Tr. Open figures represent pre-treated group, closed figures, the empirically-treated group.

duration of surgery for high- and low-lesion patients was $64 \cdot 5 \pm 7 \cdot 7$ and $76 \cdot 1 \pm 7 \cdot 9$ minutes, respectively, $P>0.05$. The high-lesion patient group had a lower mean age $(25.7 \pm 2.4$ years vs. $33.9 \pm 4.0$ years $)$ and a greater mean body weight $(72 \cdot 8 \pm 5.2 \mathrm{~kg} v s .60 \cdot 6 \pm 2.5 \mathrm{~kg})$ than the low-lesion group, both parameters showing differences of possible statistical significance $(P<0.05$ and $P<0.025$, respectively). No patient developed the clinical manifestations of the fully developed syndrome of autonomic hyperreflexia.

\section{Discussion}

The acute cardiovascular changes which are the major stigmata of the syndrome of autonomic hyperreflexia were first clearly described by Guttmann and Whitteridge, 1947, 30 years after Head and Riddoch described the symptoms of diaphoresis, nasal congestion, agitation, and severe throbbing headache (Head and Riddoch, I9I7). The neuroanatomic basis of the syndrome was defined by Kurnick, 1956. Autonomic hyperreflexia occurs in patients who have had spinal cord transection involving the lateral spinothalamic tracts and dorsal columns; when the lesion level is midthoracic or higher, the preganglionic sympathetic neurons originating below the transection are removed from inhibitory influences which descend from higher cord and brain stem centers. Thus, if distension of a hollow viscus produces strong afferent input which enters the intact cord below the lesion, an autonomic 
spinal reflex arc with uninhibited efferent activity is completed. Uncontrolled sympathetic ganglion activity then occurs in those areas of the body deriving their sympathetic innervation from cord segments below the transection. Intense arteriolar constriction in skin and viscera can produce severe arterial hypertension with pounding headache and a bradycardia mediated by the carotid sinus reflex arc. The incidence of this phenomenon in untreated, susceptible patients may be as high as 90 per cent (Johnson et al., I975; Snow et al., I977).

Subarachnoid block and general anaesthesia suppress or prevent $\mathrm{AH}$, but both approaches have limitations when applied to the paraplegic patient. Lumbar puncture is often difficult because of abnormalities of soft tissue and the vertebral column (Desmond, 1970). General anaesthesia is almost always associated with some degree of postoperative respiratory depression, a situation poorly tolerated in patients with chronic paralysis of the accessory muscles of respiration who are already at high risk for the development of atelectasis and pneumonia (Rocco and Vandem, I959).

An alternative technique for control of $\mathrm{AH}$ has been ganglioplegia with agents such as hexamethonium (Rocco and Vandam, I959), guanethidine (Shea et al., 1973), trimethaphan (Snow et al., 1977) or, recently, pentolinium tartrate (Basta et al., 1977; Textdr et al., 1976). Pentolinium is believed to act at ganglionic receptor sites for acetylcholine by stabilising the resting potential of the post-synaptic membrane. Blockade of ganglionic transmission interrupts the efferent limb of the reflex pathway responsible for the acute, severe hypertension of AH. Ganglioplegia may cause bladder and bowel atony, cycloplegia, and xerostomia, but persistent postural hypotension is the most significant complication. All patients in our study were kept at complete bed rest for 6 hours after receiving pentolinium to prevent postural hypotension, and were given intravenous fluids until the day after surgery in anticipation of the expected gastrointestinal atony. One patient developed a generalised urticarial eruption $45 \mathrm{~min}$ after pentolinium injection; this appeared to be an allergic reaction, and responded to treatment with an antihistaminic agent, diphenhydramine.

\section{Conclusions and Summary}

In our study, the effectiveness with which pentolinium controlled reflex hypertension in spinal cord injured surgical patients was related to the level of the lesion. Pentolinium $5 \mathrm{mg}$ IV prevented significant elevation of blood pressure intraoperatively in the group of patients with lesions below $\mathrm{T}_{\mathrm{I}}$; prophylactic administration of pentolinium appeared to give slightly better control than did empirical treatment.

Patients with cord transections above $T_{I}$ had a more dramatic cardiovascular response to pentolinium infusion and to surgical stimulation than did low lesion patients. Pentolinium $5 \mathrm{mg}$ IV prior to surgery produced a ganglioplegia that was of sufficient intensity to cause an initial decrease in blood pressure, but not adequate to prevent an elevation of systolic pressure during surgery. The empirically treated patients with high lesions demonstrated similar elevations of blood pressure, but in neither group was the bradycardia of the fully developed syndrome of autonomic hyperreflexia (Cole et al., 1967; Guttmann, I976) apparent.

We conclude that with appropriate adjustment of dosage, pentolinium ganglioplegia is a suitable technique for safe, convenient control of the cardiovascular stigmata of autonomic hyperreflexia. For comparable degrees of surgical stimulation, the effectiveness of a given dose of pentolinium appears to be a function I6/4-B 
of the level of the spinal cord lesion, and to a lesser extent, the time of administration.

\section{RÉSUMÉ}

Le tartrate de pentolinium (Ansolysen) par voie intaveneuse est un moyen efficace de baisser les poussées d'hypertension associées avec l'hyperréfiexie autonome. On a trouvé, chez 29 malades avec la moelle traumatisée à un niveau inférieur à $\mathrm{Dl}$, a suffit pur prevenir des poussées de la pression arterielle pendant la chirurgie. Chez les maldes avec lesions supérieures à $\mathrm{Dl}$, des doses supplementaires de pentolinium par voie intraveneuse étaient requises pour controller la tension arterielle. L'efficacité d'une dose donnée de pentolinium, pour le même degré de stimulation chirurgicale, semble être une fonction du niveau de la lesion de la moelle.

\section{ZUSAMMENFASSUNG}

Hochdruck, hervorgerufen durch autonome Hyperreflexa, kann durch entsprechende Dosierung von Pentolonium i.v. vermieden werden. In 24 Patienten mit Rückenmarksschädigung, deren Verletzung unterhalb $\mathrm{T}_{\mathrm{I}}$ lag, konnte ein signifikanter Blutdruckansteig durch intravenöse Verabreichung von $5 \mathrm{mg}$ Pentolonium verhindert werden. Patienten mit Rückenmarksverletzungen oberhalb TI benötigten zusätzliche Gaben von Pentolonium zur Blutdruckkontrolle. Bei vergleichbarer chirurgischer Stimulierung scheint die Effecktivität einer gegebenen Dosis von Pentolonium von der Höhe der Rückenmarksläsion abzuhängen.

\section{REFERENCES}

Basta, J. W., Niejadlik, K. \& Pallares, V. (I977). Autonomic hyperreflexia : intraoperative control with pentolinium tartrate. Br. F. Anaesth., 49, 1087.

CARON, C. F. \& BORS, E. (I970). A study of vascular changes during surgery of paraplegic patients. Paraplegia, 7, 292.

Cole, T. M. Kottke, F. J., Olson, M., Stradal, L. \& Niederloh, J. (1967). Alterations of cardiovascular control in high spinal myelomalcia. Arch. Phys. Med. Rehab., 48, 359.

Desmond, J. (1970). Paraplegia : problems confronting the anesthesiologist. Can. Anaesth. Soc. F., 17, 435 .

Guttmann, L. (I976). Spinal Cord Injuries Comprehensive Management and Research, 2nd ed. Blackwell Scientific Publications Ltd., Oxford.

GutTMANN, L. \& WhitTeridge, D. (I947). Effects of bladder distension on autonomic mechanisms after spinal cord injuries. Brain, 70, 36r.

HEAD, H. \& RIDDOCH, G. (I9I7). The automatic bladder, excessive sweating and some other reflex conditions in gross injuries of the spinal cord. Brain, 40, I88.

Johnson, B., Thomason, B., Pallares, V. \& Sadove, M. S. (1975). Autonomic hyperreflexia: a review. Military Med., 140, 345.

KURNICK, N. B. (1956). Autonomic hyperreflexia and its control in patients with spinal cord lesions. Ann. Intern. Med., 44, 678.

Rocco, A. G. \& VANDAM, L. D. (I959). Problems in anesthesia for paraplegics. Anesthesiology, 20, 348 .

Shea, J. D., Gioffre, R., Carrion, H. \& Small, M. P. (1973). Autonomic hyperreflexia in spinal cord injury. South. Med.F., 66, 869.

Snow, J. C., Sideropoulos, H. P., Kripke, B. J., Freed, M. M., Shah, N. K. \& SchlesINGER, R. M. (I977). Autonomic hyperreflexia during cystoscopy in patients with high spinal cord injuries. Paraplegia, 15, 327.

Texter, J. H., ReECE, R. W. \& HRANOWSKY, N. (1976). Pentolinium in the management of autonomic hyperreflexia. F. Urol., 116, 350. 